\title{
Real Options Theory and EU Member States Energy Investment Strategies
}

\author{
Tilemahos Ethimiadis ${ }^{1}$ and Dimitrios Mavridis ${ }^{2}$ \\ ${ }^{1}$ Energy Security, Systems and Markets Unit, Institute for Energy and Transport, Joint Research Centre, \\ European Commission \\ ${ }^{2}$ University of Luxembourg*
}

\begin{abstract}
According to the European Commission's latest energy and climate proposals ("Europe 2030"), Member States will be obliged to draft National Action Plans for competitive, secure and sustainable energy. In particular, these plans need to simultaneously address issues of achieving domestic objectives regarding renewable energy, energy savings, energy security, research and innovation, greenhouse gas emissions, nuclear energy, shale gas, carbon capture and storage, European Union level climate and energy objectives etc. Furthermore, coordination with neighboring Member States as well as regional effects will also have to be taken into consideration.

Drafting these medium and long-term plans may be a challenging task for the Member States, especially given the uncertainties that the energy sector faces. In this paper, we examine how real options theory can be utilized to formulate these national plans, especially the underlying Member State energy investment strategies, through illustrative examples.
\end{abstract}

Keywords: Infrastructure, Investments, Energy, Finance, Real Options

\section{INTRODUCTION}

Energy is at the core of economic and social activity in industrialized countries. The future of the energy sector in Europe has been receiving increased attention. In particular, the International Energy Agency is anticipating an increasing EU reliance on imported oil from around $80 \%$ today to more than $90 \%$ by 2035 , while gas import dependency is expected to rise from $60 \%$ to more than $80 \%$. In 2012, Europe's oil and gas import bill amounted to more than 400 billion representing some $3.1 \%$ of EU GDP. ${ }^{1}$ Simultaneously, policies aimed at reducing and mitigating climate change also receive much attention, at least within the confines of the European Union.

On January 22, 2014 the European Commission proposed energy and climate objectives, to be met by $2030 .{ }^{1}$ According to the relevant Communication by DG ENER, "The objectives send a strong signal to the market, encouraging private investment in new pipelines and electricity networks or low-carbon technologies." One of the innovations of these proposals is the New Governance System, according to which, Member States will be obliged to draft and submit National Action Plans (hereafter "national plans") for competitive, secure and sustainable energy. In particular, these plans will have to simultaneously address issues of achieving domestic objectives regarding

1 Communication from the Commission to the European Parliament, The Council, The European Economic and Social Committee and the Committee of the Regions: A policy framework for climate and energy in the period from 2020 to 2030. COM(2014) 15 final. URL: http:// eur-lex.europa.eu/LexUriServ/LexUriServ.do?uri=COM:2014:0015:FIN:EN:PDF 
greenhouse gas emissions, renewable energy, energy savings, energy security, research and innovation, nuclear energy, shale gas, carbon capture and storage, achieving European Union level climate and energy objectives etc. Furthermore, coordination with neighboring Member States, as well as regional effects, must also be taken into consideration.

In this context, Member States face increased challenges in designing strategies that are subject to unforeseen contingencies, especially as there is an explicit requirement by the European Commission for formulating long-term and overall investment strategies for energy.

In this paper, we identify the challenges and in particular the tradeoffs that Member States will face in drafting their national plans. Furthermore, this paper examines the possibility of using real option theory methodologies for drafting these national plans. We focus on two sets of issues that the proposed methodological framework fruitfully addresses. First, we present and categorize uncertainties to which national plans are subject to, with illustrations of typical cases. Secondly, we illustrate the ability of the Real Options framework in addressing strategic questions across Member States, as well as within a certain Member States energy industry.

\section{WHAT IS REQUESTED FROM THE MEMBER STATES}

Three key elements are identified from the European Commission's relevant press release on the "2030 climate and energy goals for a competitive, secure and low-carbon EU economy":?

- New targets: For example, there is a requirement of reducing greenhouse gas emissions by $40 \%$ below the 1990 level, an EU-wide binding target for renewable energy of at least $27 \%$ and renewed ambitions for energy efficiency policies.

- A new governance system: "The 2030 framework proposes a new governance framework based on national plans for competitive, secure and sustainable energy. Based on upcoming guidance by the Commission, these plans will be prepared by the Member States under a common approach, which will ensure stronger investor certainty and greater transparency, and will enhance coherence, EU coordination and surveillance. An iterative process between the Commission and Member States will ensure the plans are sufficiently ambitious, as well as their consistency and compliance over time." (emphasis in original)

- A set of new indicators: "to ensure a competitive and secure energy system."

In particular, regarding the New Governance System, the European Commission's communication ${ }^{1}$ states that: "Meeting the relevant targets would be met by a mix of Union measures and national measures described in Member States' national plans for competitive, secure and sustainable energy which would: ensure that EU policy objectives for climate and energy are delivered, provide greater coherence of Member States' approach, promote further market integration and competition and provide certainty to investors for the period after 2020."

Furthermore, is stated that: "The explicit aim should be to create more investor certainty and greater transparency; to enhance coherence, EU coordination and surveillance, including assessment of such plans against Union level climate and energy objectives, and progress towards the objectives of the internal energy market and state aid guidelines."

The evolution of the energy sector in Member States will be monitored by a set of new and informative energy indicators that will examine energy price differentials, diversification of energy imports, deployment of smart grids and interconnections, intra-EU coupling of energy markets, competition and market concentration (national and regional scale) and technological innovation. Therefore, these indicators, their dynamic and evolution, will indirectly identify the effects the implementation of the national plans.

The compilation of national plans should be a challenging task for many of the Member States. Compiling complete, proper and realistic national plans are of particular interest for the Member States, especially as these will potentially be a prerequisite for obtaining funding from cohesion/structural programs.

2 European Commission (2014), Press release: 2030 climate and energy goals for a competitive, secure and low-carbon EU economy, IP/14/54 22/01/2014. URL: http://europa.eu/rapid/press-release_IP-14-54_en.htm 


\section{METHODOLOGICAL APPROACH FOR MEDIUM AND LONG-TERM ENERGY INVESTMENT STRATEGIES}

This section focuses on the national plans' energy sector investment projects.

Project investment decisions are usually based on the Discounted Cash Flow (DCF) methods, in particular in the Net Present Value traditional capital budgeting framework. However, in the case of medium and long term energy investments strategies, there are two key components which render these methods inappropriate:

1. Dealing with uncertainties. DCF considers immediate, irreversible investments. In other words, it is assumed that an investment is immediately implemented and committed to sturdily, and thus, it cannot be undone and have the expenditures recovered. Alternatively, it presupposes that if a project is not undertaken at a certain time then it will not be able to be undertaken in the future. ${ }^{3}$ Thus, the traditional framework is unable to embody the possibility of discretionary actions at a future date that will capitalize on unexpected opportunities arising in the course of the project, as well as mitigate the losses of an unforeseen challenge.

2. Internalizing externalities. When taking investment decisions private companies usually do not take into account the positive and negative externalities that are produced as a result of an individual actor's activity. However, it is desirable that Member States compile their national plans while simultaneously viewing the whole system and the interactions between investments and other stakeholders. Hence, the traditional capital budgeting framework abstracts from strategic considerations.

Due to the above mentioned shortcomings of the traditional capital budgeting framework and the fact that they are designed more for individual projects rather than for an overall policy strategy, an alternative methodology must be adopted. One such alternative is the real options methodology which provides the decision maker with flexibility for evaluating different scenarios with high levels of uncertainty. In particular, "real options provide the owner with the right, but not an obligation, to take action". ${ }^{4}$ Thus, an "option" may refer to the right of a project initiator to defer the investment decisions, to abandon a project at a later stage, to change the operating scale, to switch inputs and outputs, to expand or contract etc. ${ }^{5}$

In other words, as there is uncertainty as to when, and how, environmental or other conditions will eventuate, the real options methodology provides increased flexibility, e.g. as to the timing of the relevant project(s) and constitutes optionality.

With real options theory, the assumption is that projects should not only be evaluated based on their current state, but all their future opportunities should be evaluated as well. ${ }^{6}$

In the context of this paper, important components of real options theory are the so-called sequencing options. In particular, these options provide flexibility as to the timing of more than one inter-related projects, that is, whether it is advantageous to implement these sequentially or in parallel. A firm or a government may prefer to defer the continuants of an investment so as to first evaluate the outcomes of a first project. In this manner, the policy maker can address, or even resolve, some of the uncertainty relating to the overall venture, before deciding whether to proceed or not with the development of the other projects. For example, the "option to expand" in the case of energy production from renewable sources subsidies, would allow to select between a number of different competing projects on the basis of the future growth potential and initial investment at an early (test) stage. Given that the concept is working, additional investment can be allocated. ${ }^{6}$

Another key component of the real options methodology is that it is scalable and thus can be introduced for a single power generator and also for a whole energy system. Examples for the latter for renewables are provided for Turkey, ${ }^{7}$ Taiwan $^{8}$ and for the USA. ${ }^{9}$

3 Fernandes, B., Cunha, J., \& Ferreira, P. (2011) The use of real options approach in energy sector investments. Renewable and Sustainable Energy Reviews 15(9), 4491-4497.

4 Frayer, J., \& Uludere, N. Z. (2001). What is it worth? Application of real options theory to the valuation of generation assets. The Electricity Journal, 14(8), 40-51.

5 Trigeorgis L. (2000) Real options: a primer. In Alleman, J. and E. Noam (eds) The new investment theory of real options and its implication for telecommunications economics, Springer, 3-33.

6 Sadowski, B. (2007), New Perspectives of Real Options Theory for Policy Analysis, Working Paper, University of Technology Eindhoven.

7 Kumbaro lu, G., Madlener, R., \& Demirel, M. (2008). A real options evaluation model for the diffusion prospects of new renewable power generation technologies. Energy Economics, 30(4), 1882-1908.

8 Lee, S. C., \& Shih, L. H. (2010). Renewable energy policy evaluation using real option model-The case of Taiwan. Energy Economics, 32, S67-S78.

9 Davis, G. A., \& Owens, B. (2003). Optimizing the level of renewable electric R\&D expenditures using real options analysis. Energy Policy, 31(15), 1589-1608, 
Furthermore, through real options methodology one can consider valuation framework as a multi-dimensional real options problem involving path-dependent (dis-) investment decisions (e.g. multiple options on multiple underlying assets, investment synergies, learning effects, a dynamic budget). An interesting point is that an increase of the volatility of an underlying asset could increase the value of a portfolio of real options related to this asset, but it could also reduce the value of a portfolio of real options.

A key component of formulating these plans regards the uncertainties that accompany all medium and long-term energy strategies. In particular, there are many sources of uncertainties which directly affect investment decisions such as: evolution of energy costs and prices (e.g. extreme fluctuations of oil prices), shifts in geopolitics (e.g. the Ukrainian situation), development of new technologies (e.g. fusion reactors) and energy sources (e.g. unconventional hydrocarbons), social acceptance for new investments (e.g. transmission lines, wind turbines), available funding (e.g. economic crises) etc. Thus, it is necessary to follow an integrated approach for formulating the necessary energy investment strategies. This approach must be able to take into consideration the above uncertainties, as well as the fact that the policies should be flexible to adapt to new situations and also take into account that there will be a discrepancy between those who formulate the plans and those who will need to implement them (i.e. governments have a shorter lifespan than the medium-term plans that they formulate).

\section{SUMMARY}

European Union Member States will be obliged to formulate single energy and climate national plans for competitive, secure and sustainable energy. In these plans, they will have to simultaneously address issues of achieving domestic objectives regarding greenhouse gas emissions, renewable energy, energy savings, energy security, research and innovation, achieving European Union level climate and energy objectives etc. Furthermore, coordination with neighboring Member States as well as regional effects must be taken into consideration. Therefore, the Member States will have to formulate medium and long-term energy investment strategies. However, there are currently no available analytical tools for this challenging task.

In this paper, we explore the uncertainties that Member States have to address while formulating these national plans. Furthermore, we examine how real options theory can be utilized to formulate these national plans, especially explicit energy investment strategies, through illustrative examples. 